\title{
Cognição, afeto e desenvolvimento humano: a emoção de viver e a razão de existir
}

\section{Cognition, affectivity, and human development: the emotion of living and the reason of being}

\author{
Helga Loos* \\ René Simonato Sant'Ana**
}

É preciso viver, não só existir..

(Plutarco)

\begin{abstract}
RESUMO
Trata-se de um convite à reflexão, no sentido de fornecer elementos, provenientes da filosofia e da psicologia, na intenção de contribuir para uma visão mais crítica e produtiva da atividade científica, bem como para um resgate da amplitude da vida. Defende-se que sejam consideradas, sobretudo, as relações entre os fenômenos - sejam estes sociais ou naturais -, em lugar de uma postura fragmentada e individualista perante o mundo. Toca questões ligadas à atitude - como forma de ver e estar no mundo -, à ética, ao desejo, ao conhecimento, ao afeto e à consciência. Explora a visão não apenas dialética, mas também monista de Vygotsky acerca da construção e da expressão humana - a qual se inspirou em autores tais como Espinosa -, segundo a qual os processos psíquicos formam-se a partir de relações de interdependência entre aspectos sociais, cognitivos, afetivos e do âmbito

* Graduada em Psicologia, Doutora em Psicologia, Desenvolvimento Humano e Educação pela Unicamp. Professora do Departamento de Teoria e Fundamentos da Educação, Universidade Federal do Paraná. E-mail: helgaloos@yahoo.com.br

** Graduado em Filosofia, Mestre em Educação pela Universidade Federal do Paraná. Professor da Fies - Paraná. E-mail: renesimonato@gmail.com
\end{abstract}


LOOS, H.; SANT'ANA, R. S. Cognição, afeto e desenvolvimento humano: a emoção de viver e a razão de existir

da ação. Uma perspectiva que supera o tradicional dualismo entre a razão e a emoção, contribuindo para uma compreensão mais integrada e mais dinâmica dos indivíduos. Apresenta-se, assim, um apelo à busca da razão e da emoção de viver na dimensão da existência humana.

Palavras-chave: sociointeracionismo; monismo; ética; cognição; afetividade.

\begin{abstract}
This article consists of an incentive towards reflection, providing elements of philosophy and psychology to contribute to a more critic and productive view of scientific activity, as well as recall the amplitude of life. It suggests a position supported primarily by the connections between different phenomena, instead of a fragmented and individualist opinion. It also addresses questions related to the attitude - as a way of living -, ethic, desire, knowledge, affection, and consciousness. The authors explore Vygotsky's monist view towards human construction and expression - which is inspired by authors like Espinosa - and according to which the psychological processes are created based on interdependent social, cognitive, affective, and behavioral aspects. It presents a perspective beyond the traditional dualism of emotion and reason, granting a more integrated and dynamic comprehension of individuals. As such, this text calls for a search of reason and emotion of living in the human existence dimension.
\end{abstract}

Key-words: social interactionism; monism; ethics; cognition; affect.

\title{
A atitude intelectual nas ciências
}

O trilho, antropológica e historicamente constituído, para a formação educativa humana, a aprendizagem e a cognição, são as ciências. As ciências são prismas de visão sobre uma mesma realidade, de "um verso só" - de um mesmo universo -, o qual perfaz e imprime a tudo e a todos as mesmas leis de existência. Cada ciência, na busca das leis da natureza, é uma atitude intelectual humana e, como atitude, é uma orientação seletiva e ativa do homem em face de uma situação ou de um problema qualquer. Nesse caso, o que está presente no limiar de cada ciência é captado em seu significado prático e antecipatório como um indício do que está além: é a possibilidade da abstração e da teorização do mundo. 
Para Jaspers (1971, introdução, § 4), "as atitudes são disposições gerais, suscetíveis, ao menos em parte, de pesquisa objetiva, assim como as formas transcendentais no sentido kantiano. São as direções do sujeito e utilizam determinada rede de formas transcendentais". Isto é, a atitude expressa em cada ciência pode ser definida como um projeto, o qual se perfaz pelo comportamento que permite efetuar opções de conceitos ou valores diante de determinada forma ou situação (analisada) do mundo.

Pode-se dizer, desta feita, como cada ciência é fruto de certo conjunto de atitudes, como também de comportamentos deliberados para se analisar o que há além, o que existe como possibilidade de conhecimento, é estranho que se privilegie, ou pior, que se anuncie como o correto, o verdadeiro, uma ciência exclusivamente ou uma atitude peculiar. Pareceria mais adequado poder convergir atitudes, relacioná-las às disciplinas, e até mesmo às concepções variáveis dentro de cada uma delas. Em poucas palavras, a atitude exige, primeiramente à ação, ser reconhecida em sua orientação emotiva e que, a partir de então, se conceba um plano de idéias, um núcleo, portanto um ponto, uma postura para se agir; por isso é uma atitude. Uma ciência - um ponto possível para se articular na totalidade - é apenas uma forma de se mover na amplitude, logo, jamais será a plenitude. A "ati-tude" é a substancialização da idéia do "ato", do "ater", do "dizer respeito a"; e o "atinente" é o ente, o ser que se põe a "dizer algo a respeito de alguma coisa" - nunca de tudo -, logo, age em um foco descritivo que fala sobre e que verifica algo da realidade.

\section{Uma questão humana - logo, também, afetiva, ética e moral}

Não se pode perder de vista que essas atitudes são oriundas das sensações humanas e de sua posterior depuração cognitiva, que, por sua vez, perpassa o crivo, primeira e fundamentalmente, do sentimento - literalmente ("senti(r)mento"), a "ação ou resultado da ação expressa pelo verbo (sentir)"; é, também, "o instrumento da ação" de sentir ou, ainda, a "coleção" (e aí é preciso um substantivo) das sensações - é uma faculdade humana, antropológica, que permite referenciar algo em um contexto de harmonia em relação ao todo. Assim, o que se sente, e o que se verifica ou calcula, apreende-se: de algo em relação à totalidade.

Como o homem não tem a capacidade, em e pelo seu consciente, de ver o todo, tudo ao mesmo tempo, desenvolveu o sentimento, que pode ser a ação expressa, resultante do sentir, como um "dispositivo" de apreensão de aspectos relativos ao todo, tal qual o instinto, em um primeiro momento; a intuição, em um estágio mais apurado; e a consciência - como idéia de saber 
LOOS, H.; SANT’ANA, R. S. Cognição, afeto e desenvolvimento humano: a emoção de viver e a razão de existir

e conhecimento - em um estado mais avançado de desenvolvimento intelectual, no qual as faculdades da razão se mostram mais notórias e como guia final das ações humanas.

Ao se postar diante do mundo, o homem sabe - já que também faz parte do mundo e contém, como toda partícula, como toda interconexão, a essência deste -, mas não sabe como - em sua existência particular, subjetiva; pois necessita processar e "sossegar" a exposição empírica a que se submeteu, como o assentar da massa que precisa "descansar" antes de assar e virar alimento (o pão) ou o envelhecimento da bebida que, com a paciência do tempo, concretiza melhor o sabor -, eis o sentimento, sendo a emoção o êxtase, o sabor, desse "saber" a priori.

Contudo, há uma espécie de "intervalo" entre o sentimento e a ação (referenciada ao sentimento): as paixões. Nesses intervalos, o homem pode tanto efetivar o linear prazer do conhecimento lato - se decompor e abstrair seu "sentimento" relacional ao mundo - quanto se interromper no circular prazer do conhecimento estrito - se decompor e abstrair seu "sentimento" em relação a si mesmo somente. No domínio dos fenômenos, o poder corrompe e o egoísmo, essa subjetividade exacerbada, leva o homem a priorizar os instrumentos provocadores das paixões estritas na forma institucionalizada, social, de existir que se autodeterminou: o dinheiro, a informação da técnica, o espírito da produção, o paradigma lógico-matemático estrito, etc. Disso decorrem vazios que desestabilizam o reconhecimento da compreensão que o homem deve ter de si mesmo e do mundo.

Afinal, quando se concentra demais num ponto - e se sabe e se sente que a realidade é um sistema e que, portanto, tem interligações, perfazendo-se sempre por mais de um ponto -, o outro (ou outros) fica em desvantagem, enfraquecido. Se uma dada atitude origina uma forma de ver - saber, no sentido clássico - o mundo, é preciso conscientizar-se ou "cientificizar-se" com perícia, com virtude. De acordo com Aristóteles:

A virtude é, portanto, uma disposição adquirida voluntária, que consiste, em relação a nós, na medida, definida pela razão em conformidade com a conduta de um homem ponderado. Ela ocupa a média entre duas extremidades lastimáveis, uma por excesso, a outra por falta. Digamos ainda o seguinte: enquanto, nas paixões e nas ações, o erro consiste ora em manter-se aquém, ora em ir além do que é conveniente, a virtude encontra e adota uma justa medida. Por isso embora a virtude, segundo sua essência e segundo a razão que fixa sua natureza, consista numa média, em relação ao bem e à perfeição, ela se situa no ponto mais elevado (Aristóteles, Ética a Nicômaco, II, 6, §§ 15-18). 
Pois, como isso tudo incorre na compreensão do fundamento de como se colocar perante o mundo e a existência, é, por assim dizer, uma questão ética. E, como é necessário distinguir para se chegar ao estágio intelectual do conhecimento, os meios e as regras para se mover sobre os fenômenos da realidade, é, também, uma proposição moral.

Enfim, apesar de que, acadêmica e cientificamente falando, o saber deveria se desvincular das idéias de bem e mal, e apesar de haver um movimento emergente (bem-vindo) de não se apegar a verdades absolutas, o conhecimento humano é produzido e velado por homens, e, como tais, estes interferem não somente com suas visões racionais da realidade, mas também com suas paixões. E, por isso, muitas vezes há desvios e derivações sobre o que abarcar como conhecimentos e verdades científicas. É preciso não se esquecer de que o homem não inventa verdades, ele as descobre, desvela: põe-se a vê-las, já postas no mundo, conforme sua atitude.

\section{O conhecimento do mundo a partir de uma visão monista}

Se o homem passa a ver e, logo, a entender os fenômenos do mundo, é preciso pôr-se ao óbvio - à primeira imagem, ao primeiro sentimento: há sempre um bojo na visão, um bloco em totalidade que forma uma imagem e um sentimento. Não há no fenômeno divisões de fato, pois os pontos - os possíveis enquadramentos e focos da visão e do saber - estão unidos em articulação - só há divisão quando se considerarem os pontos como partes. O que há é um monismo: as coisas do mundo são um conjunto de unidade (mono), quer seja do ponto de vista da sua substância, quer seja do ponto de vista das leis - lógicas ou físicas - pelas quais o mundo e a realidade se ordenam e se articulam.

Assim, conforme se vê o mundo, podem-se criar teorias ora materialistas ora espiritualistas, ora físico-lógicas ora artístico-emotivas. Desta feita, não há no monismo a contraposição entre razão e emoção, nem entre estética e técnica: "o método midiológico denuncia como falso um vício de raciocínio que tem sido utilizado pela filosofia ocidental como uma virtude hereditária: o corte entre estética e técnica" (Debray, 1994, p. 117), que é um corte da mesma ordem daquele comumente feito entre a intelectualidade e a emoção, e dos seus "intervalos", a razão e a paixão. 
LOOS, H.; SANT'ANA, R. S. Cognição, afeto e desenvolvimento humano: a emoção de viver e a razão de existir

Esse método imagético é uma forma de ver o mundo, ou seja, uma atitude que perfaz o desenvolvimento do ser humano pelo conhecimento, já que este é causado por um sentimento bem peculiar inerente à condição humana: a admiração. No campo da filosofia, a admiração é assim definida:

ADMIRAÇÃO (lat. Admiratio; in. Wonder; fr. Admiration; al. Bewunderung, Saunen; it. Ammirazione) - Segundo os antigos, a admiração é o princípio da filosofia. Diz Platão: "Essa emoção, essa admiração é própria do filósofo; nem tem a filosofia outro princípio além desse; e quem afirmou que Íris é filha de Taumas a meu ver não errou na genealogia" (Teeteto, 11, 155 d). E Aristóteles: "Devido à admiração os homens começaram a filosofar e ainda agora filosofam: de início começaram a admirar as coisas que mais facilmente suscitavam dúvida, depois continuaram pouco a pouco a duvidar até das coisas maiores, p. ex., das modificações da lua e do que se refere ao sol, às estrelas e à geração do universo. Aquele que duvida e admira sabe que ignora; por isso, o filósofo é também amante do mito, pois o mito consiste em coisas admiráveis" (Metafísica, I, 2. 982 b 12 ss.). No princípio da Idade Moderna, Descartes exprimiu o mesmo conceito: "Quando se nos depara algum objeto insólito, que julgamos novo ou diferente do que conhecíamos antes ou supúnhamos que fosse, admiramos esse objeto e ficamos surpresos; e como isso ocorre antes que saibamos se o objeto nos será ou não útil, a admiração me parece a primeira de todas as paixões; e não tem oposto porque, se o objeto que se apresenta não tem em si nada que nos surpreenda, não somos afetados por ele e o consideramos sem paixão" (Paixões da Alma, II, 53). Nesse ponto, a diferença entre Descartes e Spinoza é grande: Spinoza considerou a admiração apenas como a imaginação de algo a que a mente permanece atenta por ser algo desprovido de conexão com outras coisas (Ética, III, 52 e escol.) e recusou-se a considerá-la como uma emoção primária e fundamental, e muito menos como uma emoção filosófica que esteja na origem da filosofia. A única, a contemplação imperturbável e bem-aventurada da conexão necessária de todas as coisas na Substância Divina. Atitude filosófica, para ele, é o amor intelectual a Deus. Para Aristóteles e para Descartes, a admiração é, ao contrário, a atitude que está na raiz da dúvida e da investigação: é tomar consciência de não compreender o que se tem à frente, que mesmo sendo familiar, sob outros aspectos revela-se, a certa altura, inexplicável e maravilhoso. Kant falava da admiração a propósito da finalidade da natureza, porquanto esta é inexplicável com os conceitos do intelecto (Crítica do Juízo, § 62). Por sua vez, Kierkegaard definia a admiração como "o sentimento apaixonado pelo devir" e a reputava própria do filósofo que considera o passado, como um sinal da 
não-necessidade do passado. "Se o filósofo não admira nada (e como poderia, sem contradição, admirar uma construção necessária?), é por isso mesmo estranho à história, já que, onde quer que entre em jogo o devir (que certamente é no passado), a incerteza do que seguramente se transformou (a incerteza do devir) só pode exprimir-se por meio dessa emoção necessária ao filósofo e própria dele" (Philosophische Brocken, p. IV, § 4). Whitehead disse: “A filosofia nasce da admiração” (Natureza e Vida, 1934, 1); (Abbagnano, 2003, p. 18).

Chama a atenção, entre essas definições de admiração, a de Espinosa, que, apesar de retratar e defender em sua filosofia a idéia do monismo, põe a mente como possível observadora de "algo desprovido de conexão com outras coisas". Isso pode parecer um paradoxo, já que admite a idéia de "nãoconexão". Contudo, do ponto de vista de Espinosa, trata-se de uma ação metodológica para se entender e, assim, surgirem os procedimentos cognitivos, o processo intelectual humano. Isso porque a mente é o instrumento da reflexão e esta, por sua vez, é uma forma de se "re-fletir", de "re-velar", de "espelhar" as sensações, as visões do mundo. Se a mente funcionasse como um ponto de conexão somente - pois ela é, em certa medida, também conexão -, e não como um instrumento de projeção - de conhecimento do mundo -, não poderia exercer-se como instrumento de reprodução do todo - reflexionando-se das partes ao todo do espírito humano. Pois no fundo, no sentido de representação, as partes são iguais entre si e, de uma forma ou de outra, igualmente ao todo - e, assim, não haveria o "sentimento" nem a paixão da admiração, como emoção que se transforma em desejo e que efetiva a emoção de viver e a razão de existir. Sem essa condição, daí sim, o homem só poderia ver o mundo fragmentariamente.

Espinosa permite pensar que a admiração é a imaginação de algo, algo este ao qual a mente permanece atenta por ser desprovido - esse algo, imaginado e enquadrado com aparente isolamento - de conexão com outras coisas. Aparentemente, recusou-se a aceitar a admiração - entendida dessa forma -, como uma emoção primária e fundamental ou como uma emoção filosófica justamente porque, para ele, esse "algo", alvo de admiração, não tem (ainda) a "conexão necessária de todas as coisas na Substância Divina". Portanto, ainda não é desejo, justamente por ser isolado, sem conexão (aparente) com os demais aspectos, contrariamente a outros filósofos (por exemplo, Aristóteles e Descartes), que viam a admiração como algo instigante. É o monismo levado às últimas conseqüências. Isso corrobora (com um pouco de exagero) a tese monista exposta aqui. 
LOOS, H.; SANT'ANA, R. S. Cognição, afeto e desenvolvimento humano: a emoção de viver e a razão de existir

Compreendendo o desejo (ou a ética humana) para compreender o conhecimento

Todavia, muitos optam por ver o mundo compartimentadamente. Isso porque a idéia de conhecimento, que é bom para todos, pode, conforme a atitude, variar. O que é bom para alguns pode não ser bom para outros: "bom e mau se dizem apenas num sentido relativo" (EsPinosA, 1983, p. 14), já que uma coisa considerada isoladamente não é por si mesma nem boa nem má, mas somente em relação com uma outra à qual ela é útil ou nociva para a obtenção daquilo que ama (estima). Dessa forma, qualquer coisa pode ser dita ao mesmo tempo boa ou má, sob diferentes condições.

Assim, em uma perspectiva monista, na qual Espinosa se faz expoente e inspira autores como Vygotsky, não se deve pretender efetivamente deduzir matematicamente a totalidade do real. Esse método pode ser, sim, considerado como um modelo de exposição, mas não de descoberta total, ou, pior, de invenção da verdade.

Essa visão pensa a totalidade como um princípio ontológico e metafísico, como, no sentido primário, é a idéia de Deus. Espinosa vê Deus como substância, como atributos, como modos, mas não lhe atribui necessariamente um sentido tradicional. Por exemplo, Espinosa segue Descartes (e não Aristóteles) no que se refere à noção de substância. Em compensação, seu Deus não é em nada cartesiano; não é o criador transcendente, mas a própria natureza: Deus sive natura. Atributos e modos não são estágios de uma ontologia hierárquica, nem etapas sucessivas de uma operação ou de uma emanação, mas aspectos nos quais a substância pode ser apreendida pelo intelecto. A substância tem uma infinitude de atributos, de conexões com o mundo e a realidade, mas a mente humana só consegue visualizar e conhecer dois: extensão e pensamento.

Segue-se disso que, por se tratar de uma analogia ou representação da realidade de totalidade como Deus, mas não no sentido tradicional religioso, Deus na pura imanência da substância à natureza, uma ontologia naturalista e monista, essa filosofia (ou atitude) se afasta de todas as representações antropomórficas da divindade. Isso pode valer para as ciências de hoje, as quais parecem estar fazendo apenas representações antropomórficas do conhecimento, dividindo e subdividindo o saber ao sabor das paixões humanas, incluindo-se nisso o atual estágio de "amor" exclusivo às estruturas lógico-matemáticas para o reconhecimento do saber.

Assim, conforme Espinosa, é necessária uma ética para se poder, devidamente, postar-se na visão da totalidade do mundo, do verdadeiro conhecimento. Nessa ética não há um espaço privilegiado para o moralismo, 
que tanto impregna as relações humanas e que é um obstáculo para o alicerce do conhecimento - que é uma espécie de teoria do desejo. Essa perspectiva arruína qualquer bom regramento ético - moral, no bom sentido -, pois conduz a análise da alma humana à maneira de uma antropologia positivista somente, concebida de maneira estritamente determinista. Tem-se, assim, uma negação da transcendência na ontologia, ou, nos dizeres românticos, uma negação das emoções na razão. $\mathrm{O}$ desejo pode ser observado, entendido, no corpo e no espírito, sem que nenhuma ação causal faça de um a explicação do outro. No vazio dos valores transcendentais, o desejo se torna norma. É preciso não esquecer que não se deseja uma coisa porque ela é boa; é porque se deseja que ela é qualificada como boa.

Para que o desejo não interfira mais do que deve no entendimento do conhecimento, segundo uma visão monista, é preciso se questionar sobre o que deseja o desejo. Conforme o que se pode ler em Espinosa, o poder. Mas esse poder não tem nenhuma relação com a vontade de dominação: trata-se de um poder pleno e integral, necessário ao desenvolvimento e à atividade de um ser. Enquanto aumenta o poder do ser (em ser), maior é a sua alegria; e a sua tristeza, no caso inverso. Tristeza e alegria são os afetos fundamentais dos quais derivam todos os outros. Agir bem não é, portanto, ter em vista um ideal irreal; é se realizar. Agir mal, ou viver mal, não é simplesmente transgredir mandamentos ou normas transcendentes ou sociais (exteriores ao sujeito), é se escravizar. Para Espinosa, a questão nunca é a de prescrever, louvar ou censurar, mas de compreender os mecanismos do desejo e de sua efetivação - uma espécie de jogo dos afetos ou paixões. O desejo pessoal é sempre suscetível de ser influenciado por fins exteriores, e de ser dirigido por afetos que desembocam na diminuição do poder de agir e, portanto, na tristeza.

Por conseqüência, da idéia de uma ética de fundamentos da ação no mundo, bate à porta a questão da liberdade: como e até que ponto se pode agir; enfim, o que é ser livre? Não se deve, nessa visão monista, imaginar um livre-arbítrio ao modo de Descartes, mecanicista. Pode-se ver em Espinosa uma espécie de recusa em se fazer do homem uma exceção à lei universal da necessidade: uma espécie de "um império num império". O que se coloca na questão da liberdade não é a necessidade, mas a coerção: ser livre não contra o determinismo, mas com ele e por ele, pela capacidade que é dada pelo conhecimento de dirigir os desejos no sentido da realização da alegria mais perfeita e interessante à existência (em outras palavras, ao "bem viver"). Espinosa emancipa a liberdade do livre-arbítrio, e a ética abre caminho para uma libertação pelo conhecimento adequado. 
Nesses termos, o que se descortina para o homem é a plenitude. O que não deve ser entendido como perfeição da alma. É o bem viver como amor intelectual pela "unidade única" das coisas do mundo, sem fazer deste bem viver a recompensa da virtude: o bem viver é a própria virtude.

\section{Ciência: uma atitude social ou natural? Que dúvida é esta?}

Uma excelente idéia essa tal de ciência! Uma postura que concede, sem dúvida, conhecimento. Entretanto, uma boa idéia - uma atitude da sociedade humana diante do universo -, com uma perigosa premissa (dominar a natureza) e à disposição de uma espécie ainda a desvelar sua constituição mais fundamental e característica: a consciência. Constitui-se um filão tentador aos homens céticos de sua própria condição de "membros privilegiados da natureza"; aos homens ambiciosos e de "mente estreita" (ou de consciência incompleta) quanto ao sentido de suas existências; aos homens egoístas, medrosos de não concluírem sem sofrimento suas vidas. Contrariamente, de fato, ao que deveria mesmo ser a ciência: o esclarecimento que proporciona fazer o verdadeiro homem grandioso (aquele que se abastece da devida consciência - psíquica, crítica, moral e ética). Para Rousseau:

a) "A ciência é boa em si". A prova pode ser encontrada no fato de que, sendo Deus fonte de verdades e onisciente, temos o dever de adquirir conhecimentos.

b) A ciência é, porém, fonte de vícios monstruosos para o homem e, sobretudo, para a sociedade.

c) Ela não é, pois, feita para o homem que possui o espírito demasiado estreito para nela obter grandes progressos e o coração muito carregado de paixões para deixar de dar-lhe mau emprego (Rousseau, 1999, p. 220).

Todo esse esclarecimento, enfim, levou aos métodos, que se tornaram os instrumentos de dominação à mercê de muitas consciências medíocres e que se consideram intelectualmente infalíveis, ou melhor, pseudoconsciências. In- 
felizmente, tem-se como resultado a dominação e a escravidão. Pior, a ciência se fez com o perigo da principal premissa atitudinal (dominar a natureza) e do novo método que se seguiu disso. A natureza foi domada e coisificada: a injustiça se fez com o próprio mundo, que gerou e acolheu esse espécime, o homem. E, mais, fez o mesmo consigo mesmo: o homem dominou o homem e o coisificou. E, assim, dentro da própria espécie, criou-se a injustiça social proveniente das relações de trabalho e riqueza. Esse foi o legado da "Razão das Luzes" e da sua classe promotora, a burguesia, que encerrou tudo isso sob o sistema capitalista. ${ }^{1}$

Eis, então, um triste estado de consciência sobre a realidade posta, uma consciência pactuante com a injustiça, mostrando-se indiferente ao como e quanto os diversos níveis de dominação podem ser intransigentes: do homem com a natureza e do homem com o próprio homem.

Em suma, como atitude social moderna, de uma sociedade em notória crise, a ciência irrompe em contradições e desarticulação; e o conhecimento que se emprega e se difunde como base da educação forma e desenvolve indivíduos que têm sido, ao mesmo tempo, contraditórios e desarticulados. Já uma atitude monista (ou holística, ou interdisciplinar, ou quântica, etc.) em relação ao mundo tem o poder de formar uma visão coincidente entre as possibilidades da sociedade e da natureza; pode, enfim, bem cultivar, fundamentar e estruturar o "alimento" que possibilita o desenvolvimento cognitivo - o conhecimento -, por meio de pedagogias, atitudes e estratégias de aprendizagem devidamente coerentes: éticas, no sentido primordial de bem viver, compactuando com o sentido social humano e o sentido natural humano, retirando a dúvida de qual (cons)ciência se deve ter do mundo.

\section{Considerações sobre o monismo na psicologia de Vygotsky}

\footnotetext{
${ }^{1}$ Pense-se apenas nas questões negativas decorrentes do capitalismo e sob o mesmo prisma exposto sobre a ciência: uma boa idéia usada, no âmago, por homens pseudoconscientes. Uma filosofia prática, oriunda de um conhecimento de totalidade, não deve se prontificar a nomear inimigos a combater e, sim, localizar críticas pertinentes e expô-las, buscando, com isso, avançar à consciência, na excelência do termo; daí, por suposto, alterar a realidade de forma coerente: não um combate, mas um aperfeiçoamento.
} 
LOOS, H.; SANT'ANA, R. S. Cognição, afeto e desenvolvimento humano: a emoção de viver e a razão de existir

O alimento essencial não vem das coisas, mas do nó que ata as coisas.

(Antoine de Saint-Exupèry)

A abordagem sociointeracionista de Vygotsky é definida, em linhas gerais, a partir de dois aspectos fundamentais: (1) o conhecimento humano é construído na interação entre sujeito e objeto; e (2) a ação do sujeito sobre o objeto é socialmente mediada.

Para Vygotsky, então, as funções psicológicas superiores do homem são construídas a partir de suas relações com o meio externo. Faz-se, no entanto, importante precisar que, como aponta Góes (1991), suas ações não são linearmente determinadas pelo meio e, por isso, não se constituem uma mera reprodução daquilo que o meio oferece a cada instante. Logo, seu conhecimento não é uma cópia estrita do objeto e, sendo assim, o conhecimento do mundo - como também o conhecimento de si mesmo - que cada indivíduo elabora ao longo da vida tem características peculiares, formando a sua subjetividade, sua individualidade, sua identidade.

Isso ocorre porque existe um caráter de interdependência mútua entre os planos intra-subjetivo e intersubjetivo. A teoria vygotskiana supõe, nesse sentido, a existência de um sujeito "interativo", pois a gênese de seu conhecimento não está assentada somente em recursos externos, como também, e da mesma forma, não apenas em recursos individuais. Em Vygotsky tem-se, portanto, uma dimensão social que não é simplesmente a dimensão do outro - mas uma dimensão calcada na "relação" com o outro e com os demais aspectos do meio externo, em que influências mútuas se potencializam e se atualizam.

A unidade indissolúvel composta por elementos internos e externos ao sujeito constitui o que esse autor chama de "vivência". Na vivência forma-se um interjogo entre os diversos aspectos internos de um indivíduo - destes entre si, bem como destes com os vários aspectos do meio externo (que, por sua vez, também interagem entre si) -, e que estão presentes, direta ou indiretamente, em cada situação. O significado de vivência expressa brilhantemente o caráter monista com que Vygotsky concebeu o indivíduo humano.

Assim, cada processo psíquico específico é formado por um intrincado de sentidos subjetivos formulados no espaço de vida (interno e externo) de cada um. Os fenômenos subjetivos, assim, não existem por si mesmos e nem afastados da dimensão espaço-temporal e de suas causas - e acrescenta Vygotsky, reportando-se à postura tradicional na ciência: "E, pela mesma razão, tampouco pode existir a ciência que os estuda" (VYGOTSKY, 1996, p. 26).

Dessa forma, no homem de Vygotsky, os aspectos cognitivos, afetivos, 
sociais e da atividade - ou ação - são interdependentes. Por esse motivo, a psique e o comportamento também formam uma unidade, pois “[...] a psique não existe fora do comportamento, assim como este não existe sem aquela, ainda que seja apenas porque se trata do mesmo" (VYGOTSKY, 1996, p. 17). Nessas palavras - destacando-se, sobretudo, o "porque se trata do mesmo" -, observa-se mais uma vez, claramente, sua concepção integradora e monista: a psique existe porque existe o comportamento, a atividade, a ação no mundo, sendo o inverso também igualmente verdadeiro, pois são instâncias indissociáveis e inextricavelmente complementares.

\section{A subjetividade e a identidade humana para Vygotsky}

Como explica Molon (2003), Vygotsky acaba por apresentar, nessa discussão, sua concepção de "eu". O eu se constrói na relação com o outro, em um sistema dinâmico de reflexos reversíveis. Para ele, “[...] o mecanismo da consciência de si mesmo (autoconhecimento) e do reconhecimento dos demais é idêntico: temos consciência de nós mesmos porque a temos dos demais e pelo mesmo mecanismo, porque somos em relação a nós mesmos o mesmo que os demais em relação a nós" (VYGOTSKY, 1996, p. 17-18). Assim, o contato com os outros sujeitos permite, a cada indivíduo, o reconhecimento do outro e, por meio disso, o autoconhecimento; assim como também o reconhecimento do outro passa pelo reconhecimento do eu, em uma dinâmica não somente dialética, mas também monista, já que existe identidade e unidade entre esses processos, isto é, eles acontecem pelo mesmo mecanismo.

Tal raciocínio aplica-se também ao serem considerados os quatro planos genéticos de desenvolvimento defendidos por Vygotsky. A subjetividade, em seu contínuo processo de construção, é, por um lado - do ponto de vista da microgênese -, peculiar a cada ser humano, pois varia de acordo com os eventos constituintes de sua história particular; mas é, em sua ontogênese, reflexo de uma identidade mais ampla, a da humanidade em geral: os caminhos do desenvolvimento individual são, em certa medida, determinados pelas características da espécie, sofrendo influências da filogênese e da sociogênese.

A partir de tais considerações - e se nada apresenta existência por si só -, torna-se sem sentido criar uma atitude de contemplação do mundo em que as coisas sejam vistas de maneira fragmentária, desconectada; torna-se sem sentido qualquer ciência ou qualquer teoria que tenha olhos somente para o "seu" objeto; e torna-se sem sentido a existência de qualquer ser - mais ainda do ser humano que, por causa de sua natural fragilidade, depende essencialmente e desde o primeiro momento do outro -, quando voltada única e egoisticamente para os seus próprios interesses, pensamentos e paixões, sem considerar o 
LOOS, H.; SANT’ANA, R. S. Cognição, afeto e desenvolvimento humano: a emoção de viver e a razão de existir

"bem viver" coletivo, a sociedade, na excelência do termo.

\section{Cognição e afeto como dimensões integradas}

Coerentemente com uma visão monista, observa-se em Vygotsky a ausência da tradicional dicotomia entre pensamento e emoção, e nem entre essas duas instâncias e a dimensão social. Para ele, a vida emocional está intimamente ligada a outros processos psicológicos e ao desenvolvimento da consciência de um modo geral.

O autor denuncia ainda que, na psicologia, o capítulo das emoções sempre foi considerado a "ovelha negra" entre os demais assuntos tratados por essa ciência, excluindo-se a possibilidade de se estudar de maneira adequada o que constitui as particularidades das emoções do homem. Sempre, sim, buscou-se mostrar como devem ser reprimidas, debilitadas, eliminadas as descargas emocionais, incluindo aquelas da infância precoce. Com base na história evolutiva humana, considerou-se que a psique - entendida, nesse caso, como razão - teria necessariamente de avançar, enquanto as emoções, retroceder, provocando a "gloriosa morte de todo um setor da vida psíquica" (VYGOTSKY, 1999).

A afetividade humana encontra-se, para ele, entre as funções psicológicas superiores. E, nessa dinâmica, como aponta Molon (2003), não há um predomínio exclusivo de uma das funções, pois todas estão inter-relacionadas. Em determinados momentos, dependendo da demanda de cada situação, uma função emerge mais fortemente, estabelecendo uma hierarquia entre as funções. Essa hierarquia é, porém, circunstancial.

Vygotsky defende a existência de interconexões funcionais, nas quais os sentimentos são atravessados pelos pensamentos, e os pensamentos são permeados pelos sentimentos, e estes acontecem a partir dos e nos processos volitivos. Sob esse prisma, a função psicológica que potencializa as demais é a "vontade". A ênfase em uma ou outra função psicológica, a ser priorizada em diferentes momentos, é orientada pela vontade, a qual se constitui o mecanismo de potencialização e de realização da condição do ser humano.

Entretanto, como qualquer das funções psicológicas superiores não acontece na ausência de relações sociais que a potencializem, Vygotsky defende que a vontade é inicialmente social, interpsicológica, para, aos poucos, tomar a dimensão intrapsicológica. "Nesse sentido, o sentimento, o pensamento e a vontade - que formam a tríplice natureza social da consciência - são historica- 
mente constituídos no contexto ideológico, psicológico e cultural, considerando o biologicamente constituído" (Molon, 2003, p. 94).

Espinosa também teceu considerações acerca da relação entre a vontade e o intelecto - levando a perspectiva monista às últimas conseqüências -, pois reduziu a diferença entre essas duas instâncias a uma questão de grau. Para ele, não se trata de entidades separadas: "intelecto" é um termo abstrato e estenográfico para uma série de idéias, e "vontade", um termo abstrato para uma série de volições. Mas ambas têm a mesma relação com esta ou aquela idéia ou volição - do latim "volo" (querer) + sufixo "ção" = ação de querer -, "que a pedreira com esta ou aquela pedra". Durant (s/d) explica a concepção de Espinosa: vontade e intelecto são uma só e a mesma coisa, pois uma volição é apenas uma idéia que, pela riqueza de associações (ou talvez pela ausência de idéias rivais), permaneceu tempo suficiente no consciente para passar à ação. Cada idéia transforma-se em ação, a menos que seja sustada, na transição, por uma idéia diferente. A idéia é, ela própria, o primeiro estágio de um processo orgânico unificado, do qual a ação externa é o desfecho. Além disso, o que é freqüentemente chamado vontade deveria ser chamado desejo, que "é a própria essência do homem".

Além da vontade, Vygotsky chama a atenção para o papel das necessidades, dos motivos e da personalidade na constituição humana. Em toda vivência está presente uma ou mais necessidades. As necessidades se integram entre si, formando os "motivos", e cada motivo é uma combinação particular de sentidos subjetivos, organizados nas mais diversas áreas de atividade humana (GonZALEZ-Rey, 2000). Os motivos são extremamente importantes na discussão cognição-afeto, já que, para Vygotsky, o pensamento é gerado, em grande medida, pela motivação - lembrando que as palavras "motivação" e "emoção" têm a mesma origem: movere ou "mover" -, implicando, portanto, necessariamente, atividade. Por outro lado, como afirmam Oliveira e Rego (2003), a afetividade humana também se constitui na relação com vários outros componentes psicológicos e intelectuais. Assim, para poder emocionar-se, o indivíduo humano precisa ter também memória, pensamento, imaginação, planejamento, conhecimento, linguagem, conceitos, significados, sentidos, percepção, atenção.

E, por fim - mas não menos importante, pois se trata de um conceito central na questão da afetividade -, a personalidade é vista por Vygotsky como o que há de mais particular na subjetividade humana. A singularidade dos indivíduos é construída e se expressa, para esse autor, como um sistema complexo e integrador da vida psíquica individual. Conforme descreve Gonzalez-Rey (2000): 
Podemos apreciar como Vygotsky utiliza o conceito de personalidade para designar a integração dialética e em desenvolvimento de funções diferentes, que atingem níveis de integração qualitativa e única como sistema [...] A personalidade não representa uma entidade intrapsíquica substancializada para Vygotsky, mas sim um sistema complexo integrador da vida psíquica individual, que participa do sentido que as experiências têm para o sujeito (p. 146).

Verifica-se que, à problemática da historicamente polêmica relação entre cognição e afeto, Vygotsky apresenta, como apontam Oliveira e Rego (2003), uma abordagem essencialmente dialética, monista e desenvolvimentista.

\section{Implicações para a educação e para o desenvolvimento humano}

Pode-se detectar em alguns autores, entre eles Espinosa e Vygotsky, uma atitude que os levou a "admirar" e entender a natureza do ser humano de maneira holística - e, portanto, conectada também ao contexto social e natural mais amplo. Nessa perspectiva, cada sujeito é encarado como multiplicidade na unidade, e, ao mesmo tempo, unidade na multiplicidade. Tal postura diante do mundo tem significativas conseqüências psicológicas, ontológicas, epistemológicas, filosóficas e, portanto, educacionais.

Romper as artificiais dicotomias entre o homem e a natureza, entre o homem e os demais homens, entre esferas do funcionamento do homem no mundo possibilita que se exercite a noção de alteridade - como constituinte essencial do sujeito: do respeito fundamental, da consciência de que as coisas se constituem umas pelas outras, da cumplicidade - e não necessariamente da indiferenciação, mas da unidade.

Para o homem bem calcular e planejar o seu traçado de existência no mundo é preciso captar, pela ordem dos sentidos, os dados que comporão essa suposta equação - portanto, os sentidos precisam estar bem diligenciados - e confeccionar na ordem da emoção os núcleos essenciais de fundamentação teórica de sua existência. Pois não é na razão de viver que o homem perfaz seus princípios e, sim, na emoção de viver que encontra sentido nas coisas (SANT'ANA, 2006). A razão de viver é a explicação das faculdades intelectuais 
acerca das emoções que vitalizam o ser, nada mais. E isso não significa que a emoção de viver não seja ao mesmo tempo a razão de viver, apenas uma é que gera a outra e não o contrário: sem emoção de viver não há razão de viver; sem razão de viver, perdeu-se, primeiramente, a real emoção de viver.

\section{REFERÊNCIAS}

ABBAGNANO, N. Dicionário de filosofia. São Paulo: Martins Fontes, 2003.

ARISTÓTELES. Ética a Nicômaco. São Paulo: Nova Cultural, 1991. (Os Pensadores, 2)

DEBRAY, R. Vida e morte da imagem: uma história do olhar no ocidente. Petrópolis: Vozes, 1994.

DURANT, W. A filosofia de Espinosa. Rio de Janeiro: Tecnoprint, [19-?]. (Os grandes filósofos)

ESPINOSA, B. Pensamentos metafísicos. São Paulo: Abril Cultural, 1983. (Os Pensadores)

.Ética demonstrada à maneira dos geômetras. São Paulo: Nova Cultural, 2000. (Os Pensadores)

GÓES, M. C. A natureza social do desenvolvimento psicológico. Cadernos Cedes, Campinas, n. 24, p. 17-24, 1991.

GONZÁLEZ REY, F. El lugar de las emociones en la constitución social de lo psíquico: el aporte de Vygotsky. Educação e Sociedade, ano XXI, n. 70, 2000.

JASPERS, K. Psychologie der Weltanschauungen. Berlin: Springer, 1971.

MOLON, S. I. Subjetividade e constituição do sujeito em Vygotsky. Petrópolis: Vozes, 2003.

OLIVEIRA, M. K.; REGO, T. C. Vygotsky e as complexas relações entre cognição e afeto. In: ARANTES, V. A. Afetividade na escola: alternativas teóricas e práticas. São Paulo: Summus, 2003. 
LOOS, H.; SANT'ANA, R. S. Cognição, afeto e desenvolvimento humano: a emoção de viver e a razão de existir

ROUSSEAU, J.-J. Emílio ou da educação. São Paulo: Martins Fontes, 1999.

SANT'ANA, R. S. Rousseau e a arte de busca da consciência plena. Novos ensaios sobre a filosofia da ação e educação: críticas e razões sobre a prática do viver e da formação humana. Dissertação (Mestrado em Educação) - Setor de Educação, Universidade Federal do Paraná, Curitiba, 2006.

VYGOTSKY, L. S. Os métodos de investigação reflexológicos e psicológicos. Teoria e método em psicologia. São Paulo: Martins Fontes, 1996.

. O desenvolvimento psicológico na infância. São Paulo: Martins Fontes, 1999.

Texto recebido em 26 fev. 2007

Texto aprovado em 17 maio 2007 